\title{
Comparison of various serological assays for novel SARS-COV-2
}

\author{
María Simón Sacristan ${ }^{1}$ - Ana Collazos-Blanco ${ }^{1}$ - Maria Isabel Zamora Cintas ${ }^{1}$ - Alicia Serrano García ${ }^{1}$. \\ Carmen Ybarra de Villavicencio ${ }^{1}$ - María Mateo Maestre ${ }^{1}$
}

Received: 2 June 2020 / Accepted: 28 October 2020 / Published online: 25 November 2020

(C) Springer-Verlag GmbH Germany, part of Springer Nature 2020

\begin{abstract}
Coronavirus disease-19 (COVID19), the novel respiratory illness caused by severe acute respiratory syndrome coronavirus (SARS-CoV-2), is associated with severe morbidity and mortality. The aim of our study was to compare different immunoassays. We evaluated three immunochromatographic test (The StrongStep®SARS-CoV-2 IgG/IgM kit, AllTest COV-19 IgG/IgM kit, and Wondfo® SARS-CoV-2 Antibody) and two chemiluminescence immunoassays (CMIA) (Covid-19 VIRCLIA® IgM+IgA/ IgG monotest and the Abbott SARS-CoV-2 IgG assay) in COVID-19 patients. The assays were performed using serum samples of three group patients, i.e., healthy controls, patients with SARS-CoV-2 PCR positive, and patients with SARS-CoV-2 PCR negative clinically diagnosed of COVID-19 infection. The detection percentages of IgG with the StrongStep® SARS-CoV-2 $\mathrm{IgG} / \mathrm{IgM}$ kit and AllTest COV-19 IgG/IgM kit were similar in both groups (83.3\% and 80.6\%, respectively in group 2, $p=0.766$ ) and $(42.9 \%$ and $50.0 \%$, respectively in group $3, p=0.706)$. There were some differences on IgM detection between StrongStep ${ }^{\circledR}$ SARS-CoV-2 IgG/IgM kit and AllTest COV-19 IgG/IgM kit (11.1\% and 30.6\%, respectively in group 2, $p=0.042$ and $0.0 \%$ and $28.6 \%$, respectively in group $3, p=0.031$ ). The positive rate of IgG in group 2 is higher compared to group 3 with the two immunoassays tested. We observe the same positive rates of IgG with the two CMIA. Our study shows excellent performance of CMIA compared to immunochromatographic test and confirms its potential use in the diagnosis of the new SARS-CoV-2.
\end{abstract}

Keywords Antibodies $\cdot$ Chemiluminescence immunoassays $\cdot \operatorname{IgG} \cdot \operatorname{IgM} \cdot$ Immunochromatographic tests $\cdot$ SARS-CoV-2

$\overline{\text { María Simón Sacristan, Ana Collazos Blanco and Maria Isabel Zamora }}$ Cintas contributed equally to this work.

María Simón Sacristan

msimsac@oc.mde.es

$\triangle$ Ana Collazos-Blanco

acollazosblanco@gmail.com

Maria Isabel Zamora Cintas

maribel.zamora.cintas@gmail.com

Alicia Serrano García

alicia_sg@hotmail.com

Carmen Ybarra de Villavicencio

cybarrav@gmail.com

María Mateo Maestre

mariamateo@hotmail.com

1 Servicio de Microbiología y Parasitología, Hospital Central de la Defensa Gómez Ulla, Madrid, Spain

\section{Introduction}

Severe acute respiratory syndrome coronavirus (SARS-CoV2) [1] was discovered in December 2019 in the city of Wuhan, China. It soon spread to other cities and countries, and on 11 March 2020 was proclaimed a pandemic by WHO. The clinical symptoms of most patients are fever, sore throat, cough, and shortness of breath [2].

RT-PCR (reverse transcription polymerase chain reaction) remained the gold standard for the diagnosis of infection due to SARS-CoV-2, which has led to 974,449 coronavirus disease-19 (COVID19) cases and 33,992 deaths by 19 October 2020 in Spain. Its sensitivity did not reach $100 \%$ but it remained better than that of methods based on the detection of antigens. However, RT-PCR takes a long time to get results and qualified personnel is necessary. In several cases, RT-PCR has shown false negatives in patients with pneumonia, showing clinical and radiographic evidence compatible with COVID19; these patients were considered as clinically diagnosed of SARS-CoV-2 according to the 5th edition of guideline on diagnosis and treatment of the novel coronavirus pneumonia. 
Different studies are being developed evaluating the use of lateral flow immunoassays to help in the diagnosis of SARSCoV-2 and its use to know the seroprevalence state of the population [3-7]. Serology based on immunoassays, ELISA, or chemioluminescence [8] are being evaluated and they show more sensitivity and specificity than the lateral flow immunoassays [9, 10]

\section{Materials and methods}

Here, we present the newly developed serological detection methods targeting the viral antibody, lateral flow method, and a chemiluminescent analytical system (CLIA) that were conducted in the Hospital Central de la Defensa Gómez Ulla (Madrid).

\section{Study design}

In our study, we evaluate two chemioluminescence assays and three lateral flow immunoassays for the detection of SARSCoV-2 antibodies.

Patient serum samples used in this study were submitted to the routine Microbiology Laboratory at Hospital Central de la Defensa Gómez Ulla (Madrid) for diagnostic purposes.

\section{Study period and serum samples}

Control serum samples $(n=50)$ included archived anonymous serum obtained from healthy blood donors with no history of SARS-CoV-2 infection, between 1 September and 30 October 2019 (group 1, healthy control).

These serum samples were donated to the Microbiology Laboratory by the transfusion Center of the Armed Forces at Hospital Central de la Defensa Gómez Ulla (CTFAS).

Case serum samples were obtained from patients with SARS-CoV-2 infection $(n=50)$ between 6 March and 1 April 2020. (group 2, patients with RT-PCR_positive and group 3, patients with RT-PCR - negative, "clinically diagnosed," that means patients with pneumonia, showing clinical and radiographic evidence compatible with COVID19 according to the 5 th edition of guideline on diagnosis and treatment of the novel coronavirus pneumonia).

\section{Real-time PCR assay}

We used three types of automatic extractors to obtain viral RNA from clinical samples, i.e., MagCore HF16 (RBC bioscience, Taipei, Taiwan), Nimbus Microlab Seegene (Hamilton Company, Bonaduz, Switzerland), and m2000 system (Abbott Molecular Inc. Des Plaines, IL).

RNA amplification was made using two real-time PCR platforms, i.e., qCOVID-19 (Genomica, Madrid, Spain) and
Allplex 2019-nCoV assay (Seegene, Seoul, South Korea), and we used the CFX96 ${ }^{\text {TM }}$ (Bio-Rad) Real-Time Detection System. PCR did not have a human extraction control gene target. The extraction control gen target was a phage.

These kits were used according to the manufacturer's instructions for both the handling and the interpretation of the results.

\section{Immunochromatographic test (lateral flow method)}

We evaluated 3 immunochromatographic tests (The StrongStep®SARS-CoV-2 IgG/IgM kit, AllTest COV-19 IgG/IgM kit, and Wondfo® SARS-CoV-2 Antibody).

AllTest COV-19 IgG/IgM kit was evaluated only in group 2 and group 3 because samples from group 1 were exhausted.

The tests were performed at room temperature according to the manufacturer's instructions. For all tests, the recommended sample volume of $10 \mu \mathrm{l}$ serum was added to the sample well. These tests did not provide target information or suggestion of titer.

For the StrongStep ${ }^{\circledR}$ SARS-CoV-2 IgG/IgM kit and Wondfo® SARS-CoV-2 Antibody, 2 drops were transferred (approximately $80 \mu \mathrm{l}$ of buffer solution) to the buffer well and the result was read visually after $15 \mathrm{~min}$.

In case of the AllTest COV-19 IgG/IgM kit, 1 drop (40 $\mu \mathrm{l})$ of buffer was added, and the result was read after $10 \mathrm{~min}$.

Weak signals for $\operatorname{IgM} / \mathrm{IgG}$, together or separate, were considered positive. The samples with only $\mathrm{C}$ line were regarded as negative; the strips where no $\mathrm{C}$ line showed up should be considered as an invalid test.

The Wondfo® SARS-CoV-2 Antibody assay does not discriminate between $\operatorname{IgM}$ and $\operatorname{IgG}$.

\section{Chemiluminescence immunoassay}

\section{Covid-19 VIRCLIA ${ }^{\circledast}$ IgM+lgA monotest and Covid-19 VIRCLIA ${ }^{\circledR}$ IgG monotest (Vircell, S.L.)}

Both were performed according to the manufacturer's instructions. Prior to testing, samples should be inactivated at $56{ }^{\circ} \mathrm{C}$ for $30 \mathrm{~min}$.

Samples have been processed in VIRCLIA ${ }^{\circledR}$ analytical system of chemiluminescent. The CLIA method is based upon the reaction of anti-nucleocapsid and anti-spike antibodies in the sample tested with the antigen adsorbed on the polystyrene surface. Unbound immunoglobulins are washed off. An enzyme-labeled anti-human globulin binds the antigen antibody complex in a second step. After a new washing step, bound conjugate is developed with the aid of a chemiluminescent substrate solution that will generate a glow-type luminescence that can be read with a luminometer.

Each sample is assayed onto two reaction wells: one coated with antigen and one processed and blocked similarly to the 
reaction well except that it is not coated with antigen. The blank well is used to subtract possible unspecific backgrounds.

\section{The Abbott SARS-CoV-2 IgG assay (Abbott Laboratories Inc., IL, USA)}

This technique is a chemiluminescent microparticle immunoassay (CMIA) used for the qualitative detection of IgG antibodies to SARS-CoV-2 in human serum or plasma on the ARCHITECT System. A minimum of $100 \mu \mathrm{l}$ of serum or plasma is required.

The assay is designed to detect IgG antibodies to the nucleocapsid protein of SARS-CoV-2. Sample, SARS-CoV-2 antigen coated paramagnetic microparticles, and assay diluent are combined and incubated. The IgG antibodies to SARS$\mathrm{CoV}-2$ present in the sample bind to the SARS-CoV-2 antigen coated microparticles. The mixture is washed. Anti-human IgG acridinium-labeled conjugate is added to create a reaction mixture and incubated. Following a wash cycle, pre-trigger and trigger Solutions are added.

For both immunoassays evaluated, the resulting chemiluminescent reaction is measured as a relative light unit (RLU). There is a direct relationship between the amount of antibodies to SARS-CoV-2 in the sample and the RLU detected by the system optics.

\section{Statistical analyses}

Statistical analysis was carried out using the statistical package STATA/IC version 13.1 (StataCorp, TX, USA). Continuous data are expressed as median and IQR, while categorical data were expressed as frequencies and percentages. Comparisons between variables were made using two-tailed Fisher's exact test or $t$ test. For these comparisons, a $p$ value less than or equal to 0.05 was considered significant.

The agreement between the different serological diagnostic techniques was expressed by the Kappa Index and percentage of agreement. A Kappa value of more than 0.75 indicates good agreement between tests, while a value of less than 0.4 indicates poor agreement.

\section{Results}

The serologic results are summarized in Table 1.

\section{Evaluation of the chemiluminescence immunoassays}

Two commercial chemiluminescence immunoassays were evaluated using 50 serum samples (group 2 and group 3) and 50 control serum samples (group 1).
The positive rate of $\operatorname{IgG}$ in group 2 is higher compared to group 3 with the two immunoassays tested $(97.2 \%$ and $50.0 \%$, respectively, $p=0.001$ ). We observe the same positive rates of IgG with the two chemiluminescence immunoassays.

With the Covid-19 VIRCLIA $®$ Immunoassay, we also determine $\operatorname{IgM}+\operatorname{IgA}$. The positive rates of $\operatorname{IgM}+\operatorname{IgA}$ in group 2 are higher compared to group 3 but there was no statistical significance $(77.8 \%$ and $50.0 \%$, respectively, $p=0.054)$.

\section{Evaluation of the immunochromatographic test}

Three commercial CE-marked immunochromatographic test (lateral flow methods) for detecting SARS-CoV-2 antibodies were evaluated in the same serum samples as describe previously.

Thirty-five cases of group $2(97.2 \%)$ and eight cases of group $3(57.1 \%)$ were positive for SARS-CoV-2-specific antibodies $\operatorname{IgM}$ or IgG by at least one of the three immunochromatographic test.

Although the nucleic acid test is the "gold standard" for microbiological diagnosis, due to certain limitations, the false negative cases are not rare. Hence, the IgM and IgG antibodies were also examined in clinically diagnosed patients (group 3).

The positive rates of IgM or IgG in group 2 (RT-PCRpositive patients) are higher in comparison to group 3 in all immunochromatographic tests. The positive percentages of IgG detected with the StrongStep ${ }^{\circledR}$ SARS-CoV-2 IgG/IgM kit and AllTest COV-19 IgG/IgM kit were similar in both groups $(83.3 \%$ and $80.6 \%$, respectively in group $2, p=$ 0.766 ; and $42.9 \%$ and $50.0 \%$, respectively in group $3, p=$ 0.706). However, the positive percentages of IgM detected with the StrongStep ${ }^{\circledR}$ SARS-CoV-2 IgG/IgM kit and AllTest COV-19 IgG/IgM kit are highly different (11.1\% and $30.6 \%$, respectively in group $2, p=0.042$; and $0.0 \%$ and $28.6 \%$, respectively in group $3, p=0.031$ ).

Combining the result of IgM and IgG, in example patients with either IgM or IgG positive, we do not observe a significant increase in the percentage of positive results with any of the three assays compared with the positive rate of IgG. The combined results obtained are similar with the StrongStep ${ }^{\circledR}$ SARS-CoV-2 IgG/IgM kit and AllTest COV-19 IgG/IgM kit (83.3\% and $88.9 \%$ respectively in group $2, p=0.766$; and $42.9 \%$ and $50.0 \%$ respectively in group $3, p=0.706$ ). Wondfo® SARS-CoV-2 Antibody assay does not discriminate between $\operatorname{IgM}$ and $\operatorname{IgG}$, and the positive rate was $88.9 \%$ and $50.0 \%$, respectively, similar to the combined results of the other two assays tested.

\section{Agreement between serological assays}

To determine the agreement between the different assays evaluated, the proportion of case serum samples which shared the same result between two assays was calculated. The high 
Table 1 Serological results from the three groups of patients

\begin{tabular}{|c|c|c|c|c|}
\hline & Group $1(\mathrm{No}=50)$ & Group $2(\mathrm{No}=36)$ & Group $3($ No = 14) & $p$ value* \\
\hline \multicolumn{5}{|c|}{ StrongStep ${ }^{\circ}$ SARS-CoV-2 IgG/IgM kit } \\
\hline IgM positive no. (\%) & $0(0.0)$ & $4(11.1)$ & $0(0.0)$ & 0.194 \\
\hline IgG positive no. (\%) & $0(0.0)$ & $30(83.3)$ & $6(42.9)$ & $0.004 * *$ \\
\hline IgM or IgG positive no. (\%) & $0(0.0)$ & $30(83.3)$ & $6(42.9)$ & $0.004 * *$ \\
\hline \multicolumn{5}{|l|}{ AllTest COV-19 IgG/IgM kit } \\
\hline IgM positive no. (\%) & No data & $11(30.6)$ & $4(28.6)$ & 0.890 \\
\hline IgG positive no. $(\%)$ & No data & $29(80.6)$ & $7(50.0)$ & $0.030 * *$ \\
\hline IgM or IgG positive no. (\%) & No data & $32(88.9)$ & $7(50.0)$ & $0.030 * *$ \\
\hline \multicolumn{5}{|c|}{ Wondfo ${ }^{\circledR}$ SARS-CoV-2 Antibody } \\
\hline Total ACS positive no. (\%) & $1(2.0)$ & $32(88.9)$ & $7(50.0)$ & $0.030 * *$ \\
\hline \multicolumn{5}{|l|}{ COVID-19 VIRCLIA® } \\
\hline IgM/IgA positive no. (\%) & $2(4.0)$ & $28(77.8)$ & $7(50.0)$ & 0.054 \\
\hline IgG positive no. (\%) & $0(0.0)$ & $35(97.2)$ & $7(50.0)$ & $0.001 * *$ \\
\hline IgM or IgG positive no. (\%) & $2(4.0)$ & $36(100.0)$ & $8(57.1)$ & $0.001 * *$ \\
\hline \multicolumn{5}{|l|}{ Abott } \\
\hline IgG positive no. $(\%)$ & $0(0.0)$ & $35(97.2)$ & $7(50.0)$ & $0.001 * *$ \\
\hline $\begin{array}{l}\text { Time between PCR result and } \\
\text { serology (median, days) }\end{array}$ & Not applicable & 11.4 & 4.9 & 0.087 \\
\hline
\end{tabular}

*Statistical differences between group 2 and group 3

**A $p$ value less than or equal to 0.05 was considered significant concordant percentage was between Covid-19 VIRCLIA $®$ IgG monotest and Abbott SARS-CoV-2 IgG assay (Fig. 1) that were $96.0 \%$ concordant.

\section{Discussion}

In the present study, three lateral flow immunoassays and two chemiluminescence assays for the detection of SARS-CoV-2 antibodies were evaluated using serum samples from adult patients diagnosed for SARS-CoV-2 (group 2 and group 3) and a collection of control serum samples taken before the emergence of the virus in Wuhan in December 2019.

Our study shows that immunochromatographic tests and chemiluminescence assays are very specific, with a low rate of false positive results, both in detecting IgM or IgG antibodies $(<5 \%$, group 1$)$. These control serum samples were taken from the Transfusion Center of the Armed Forces at Hospital Central de la Defensa Gómez Ulla, so these samples were screened for transmission of other infectious diseases, so it is improbable that there was cross-reactivity.

There is increasing evidence of the usefulness of serology in the evaluation of the course of SARS-CoV-2 infection [11, 12]; due to this, there is a high interest about the usefulness of the serologic rapid test, but there is scarce information about their utility.

The differences observed between the different assays may be in part explained by SARS-CoV-2 antigen targeted and the chemiluminescence assays format [13]
Overall, we found that the lateral flow immunoassays generally presented similar results regarding $\operatorname{IgG}$, while they had greater differences in IgM detection, AllTest COV-19 IgG/ IgM kit detected a higher rate of IgM than StrongStep ${ }^{\circledR}$ SARS-CoV-2 IgG/IgM kit.

Covid-19 VIRCLIA® IgG monotest Immunoassay and Abbott SARS-CoV-2 IgG assay present same rates of positivity of IgG. We observed that the detection capacity of chemiluminescence assays in group 2 is greater than $95 \%$, while by means of lateral flow immunoassays, this value is less than $90 \%$.

When comparing results between group 3 and group 2, many differences regarding the detection of antibodies are found. The percentage of antibodies detected in group 3 is lower with any of the techniques used (immunochromatographic test or chemiluminescence assays). This could be caused either by an error in the diagnosis (the pneumonia was caused by another microorganism) or there is not enough time between the RT-PCR and the antibody development. We have no data of serial samples of group 3 patients; diagnostic performance could potentially be better if serological assay was repeated 2 weeks later. Even if a late positive sample does not help physician for acute care, it is always interesting to have a definite confirmation of diagnosis in case series or studies.

We know this study has a few limitations. First, we selected a small number of serum samples and all of them belong to patients of the same hospital. Anti-nucleocapsid CMIA platforms have limitations; some studies show $\mathrm{N}$ protein is not suitable to detect virus-specific antibodies due to very high- 
Fig. 1 Index Kappa correlation and agreement between serological results

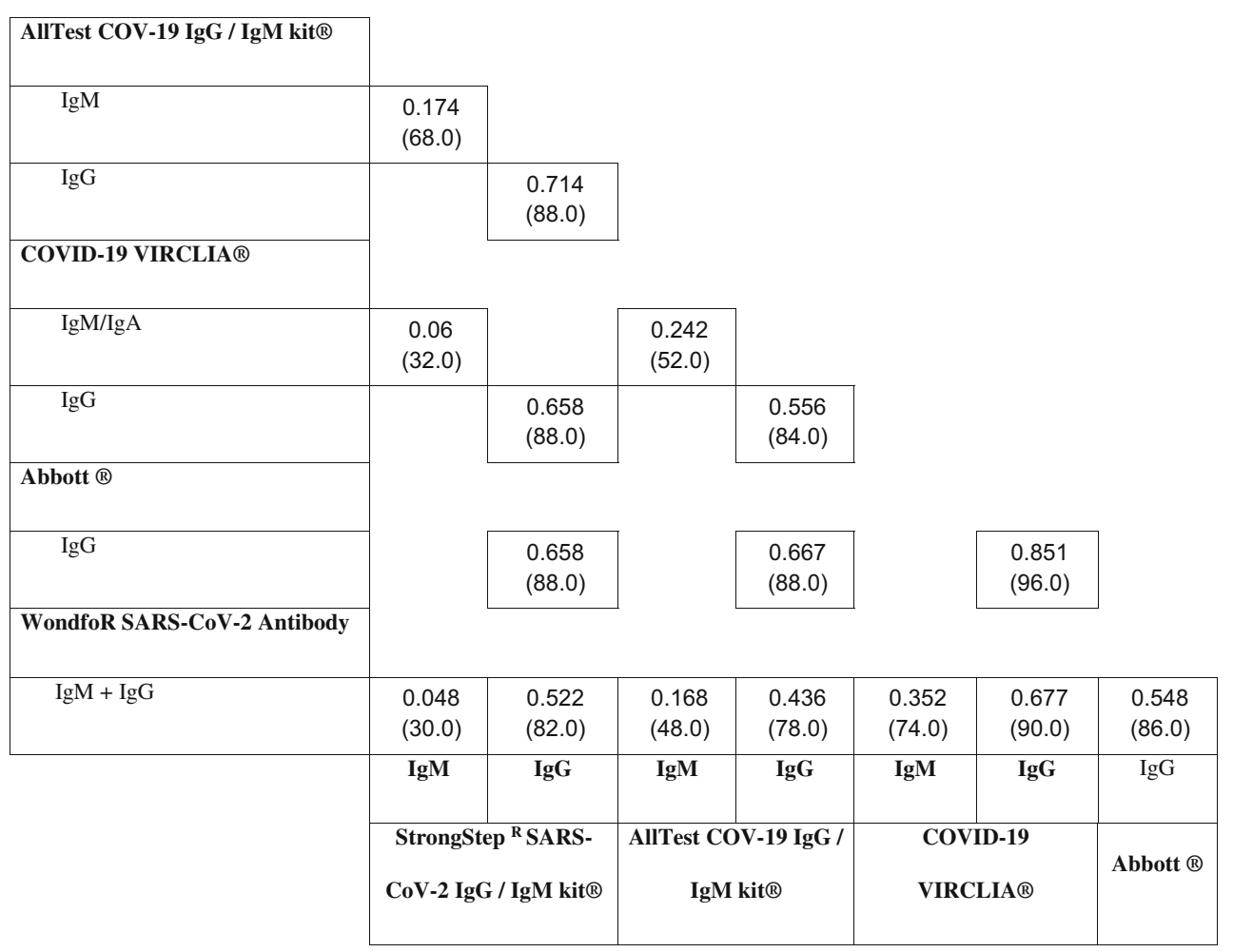

level of cross-reactivity[14]; without demonstration of subsequent IgG seroconversion, it is difficult to assume that IgM positive cases are specific. Secondly, group 3 presents a shorter time between performing the RT-PCR and serology than for patients in group 2 (4.9 and 11.4 days, respectively, $p$ $=0.087$ ). This could explain the higher rate of antibody detection in group 2 with all the assays tested. The objective of the serology in group 2 is to assess the course and the host immunity of SARS-CoV-2 infection; the objective in group 3 was to increase the evidence of SARS-CoV-2 infection in patients with RT-PCR result negative for this novel coronavirus. However, this may be the consequence of a third limitation since we ignore the exact time elapsed since the beginning of the symptoms. Most studies instigate a minimum of 14 days or in some cases 21 days since symptom onset prior to serology testing in order to avoid false negatives, reporting poor performance in the first 10 days[6].

And finally, we do not have results for group 1 (healthy control) using AllTest COV-19 IgG/IgM kit because the samples were exhausted.

To the best of our knowledge, this is one of the first studies on anti-SARS-CoV-2 IgM and IgG antibodies that compare chemiluminescence methods and immunochromatographic test (lateral flow methods). More multicenter studies with a large number of serum samples from different areas would be necessary to evaluate these techniques.

Overall, our data demonstrate excellent results with the chemiluminescence immunoassays, Abbott Architect
SARS-CoV-2 IgG Assay and Covid-19 VIRCLIA® assay, compared to immunochromatographic tests and thus its use in the diagnosis of the new SARS-CoV-2. Chemiluminescence assays could be an important component in the diagnostic approach to SARS-CoV-2 infection

Acknowledgments The authors would like to thank the team behind the Transfusion Center of the Armed Forces at Hospital Central de la Defensa Gómez Ulla (CTFAS) for facilitating serum samples.

Author contributions Study concept and design: MSS, ACB, and MZC Clinical and microbiological data acquisition: MSS, ACB, MZC, and CYV

Sample processing: MSS and ASG

Statistical analysis and interpretation of data: $\mathrm{ACB}$

Writing of the manuscript: MSS, ACB, and MZC

Critical revision of the manuscript: MMM

All authors read and approved the final manuscript.

Data availability Not applicable

\section{Compliance with ethical standards}

Conflict of interest The authors declare that they have no conflict of interest.

Ethics approval The study was conducted according to the ethical requirements established by the Declaration of Helsinki. The Ethics Committee of Hospital Central de la Defensa Gómez Ulla (Madrid) approved the study. 
Consent to participate Not applicable

Consent for publication Not applicable

Code availability Not applicable

\section{References}

1. Guan NZY, Hu Y, Liang WH, Ou CQ, He JX, Liu L, Shan H, Lei CL, Hui DSC, Du B, Li LJ, Zeng G, Yuen KY, Chen RC, Tang CL, Wang T, Chen PY, Xiang J, Li SY, Wang JL, Liang ZJ, Peng YX, Wei L, Liu Y, Hu YH, Peng P, Wang JM, Liu JY, Chen Z, Li G, Zheng ZJ, Qiu SQ, Luo J, Ye CJ, Zhu SY, Zhong NS, China Medical Treatment Expert Group for, Covid (2020) Clinical characteristics of coronavirus disease 2019 in China. N Engl J Med 382(18):1708-1720

2. Chen N, Zhou M, Dong X, Qu J, Gong F, Han Y, Qiu Y, Wang J, Liu Y, Wei Y, Xia J, Yu T, Zhang X, Zhang (2020) Epidemiological and clinical characteristics of 99 cases of 2019 novel coronavirus pneumonia in Wuhan, China: a descriptive study. Lancet 395(10223):507-513

3. Guo L, Ren L, Yang S, Xiao M, Chang YF, Dela Cruz CS, Wang Y, Wu C, Xiao Y, Zhang L, Han L, Dang S, Xu Y, Yang Q, Xu S, Zhu H, Xu Y, Jin Q, Sharma L, Wang L, Wang J (2020) Profiling early humoral response to diagnose novel coronavirus disease (COVID-19). Clin Infect Dis 71(15):778-785.

4. Pan YG, Fan J, Tang Y, Zhao J, Long X, Guo S, Zhao Z, Liu Y, Hu H, Xue H, Li Y (2020) Serological immunochromatographic approach in diagnosis with SARS-CoV-2 infected COVID-19 patients. J Infect 81(1):28-32

5. Li Z, Yang G, Fan J, Tang Y, Zhao J, Long X, Guo S, Zhao Z, Liu Y, Hu H, Xue H, Li Y (2020) Development and clinical application of a rapid IgM-IgG combined antibody test for SARS-CoV-2 infection diagnosis. J Med Virol 92(9):1518-1524

6. Zhao YQ, Wang H, Liu W, Liao X, Su Y, Wang X, Yuan J, Li T, Li J, Qian S, Hong C, Wang F, Liu Y, Wang Z, He Q, Li Z, He B, Zhang T, Fu Y, Ge S, Liu L, Zhang J, Xia N, Zhang Z (2020) Antibody responses to SARS-CoV-2 in patients of novel coronavirus disease 2019. Clin Infect Dis 71(16):2027-2034
7. Montesinos I, Gruson D, Kabamba B, Dahma H, Van den Wijngaert S, Reza S, Carbone V, Vandenberg O, Gulbis B, Wolff F, Rodriguez-Villalobos H (2020) Evaluation of two automated and three rapid lateral flow immunoassays for the detection of anti-SARS-CoV-2 antibodies. J Clin Virol 128:104413

8. Infantino M, Grossi V, Lari B, Bambi R, Perri A, Manneschi M, Terenzi G, Liotti I, Ciotta G, Taddei C, Benucci M, Casprini P, Veneziani F, Fabbri S, Pompetti A, Manfredi M (2020) Diagnostic accuracy of an automated chemiluminescent immunoassay for anti-SARS-CoV-2 IgM and IgG antibodies: an Italian experience. J Med Virol 9:1671-75

9. Bryan A, Pepper G, Wener MH, Fink SL, Morishima C, Chaudhary A, Jerome KR, Mathias PC, Greninger AL (2020) Performance characteristics of the Abbott Architect SARS-CoV-2 IgG assay and seroprevalence in Boise, Idaho. J Clin Microbiol 58(8): 00941-20

10. Jaaskelainen AJ, Kekalainen E, Kallio-Kokko H, Mannonen L, Kortela E, Vapalahti O, Kurkela S, Lappalainen M (2020) Evaluation of commercial and automated SARS-CoV-2 IgG and IgA ELISAs using coronavirus disease (COVID-19) patient samples. Euro Surveill 25(18):2000603

11. Theel ES, Slev P, Wheeler S, Couturier MR, Wong SJ, Kadkhoda $\mathrm{K}$ (2020) The role of antibody testing for SARS-CoV-2: is there one? J Clin Microbiol 58(8):00797-20

12. Zainol Rashid Z, Othman SN, Abdul Samat MN, Ali UK, Wong KK (2020) Diagnostic performance of COVID-19 serology assays. Malays J Pathol 42(1):13-21

13. Cai XF, Chen J, Hu JL, Long QX, Deng HJ, Fan K, Liao P, Liu BZ, Wu GC, Chen YK, Li ZJ, Wang K, Zhang XL, Tian WG, Xiang JL, Du HX WJ, Hu Y, Tang N, Lin Y, Ren JH, Huang LY, Wei J, Gan CY, Chen YM, Gao QZ, Chen AM, He CL, Wang DX, Hu P, Zhou FC, Huang AL, Liu P, Wang DQ (2020) A peptide-based magnetic chemiluminescence enzyme immunoassay for serological diagnosis of coronavirus disease 2019 (COVID-19). J Infect Dis 222(2):189 193

14. Chia Tan CW, Foo R, Kang AEZ, Peng Y, Sivalingam V, Tiu C, Ong XM, Zhu F, Young BE, Chen MI, Tan YJ, Lye DC, Anderson DE, Wang LF (2020) Serological differentiation between COVID19 and SARS infections. Emerg Microbes Infect 9(1):1497-1505

Publisher's note Springer Nature remains neutral with regard to jurisdictional claims in published maps and institutional affiliations. 